interventions might reduce caesarean sections moderately if not significantly. We will not know how well the project has worked or whether there will be some delayed impact of having merely published the recommendations until early in 1989. What is already clear is that without clearly targeted initiatives the multifaceted causes driving the rate of caesarean section upwards will influence doctors' behaviour far more than continued calls from researchers for a reduced rate.

JONATHAN LOMAS

Associate Professor in Clinical Epidemiology and Biostatistics and Associate Coordinator of the Centre for Health Economics and Policy Analysis,

Health Sciences Centre,

McMaster University,

Hamilton,

Ontario,

Canada L8N $3 Z 5$

The author receives personal support from the Ontario Ministry of Health, and the work is partly funded by NHRDP grant No 66063390-57 from Health and Welfare Canada.

1 Notzon FC, Placek PJ, Taffel SM. Comparisons of national cesarean section rates. $N$ Engl f Med 1987;316:386-9.

2 Feldman GB, Freiman JA. Prophylactic cesarean section at term? N Engl f Med 1985;312:1264-7.

3 Hemminki E. Obstetric practice in Finland, 1950-1980: changes in technology and its relation to health. Med Care 1983;21:1134-43.

4 Bodner B, Benjamin A, McLean FH, Usher RH. Has use of cesarean section reduced the risks of delivery in the breech presentation? Am $\mathcal{F}$ Obstet Gynecol 1986;154:244-50.
Bergsjo P, Schmidt E, Pusch D. Differences in the reported frequencies of some obstetrical interventions in Europe. Br f Obstet Gynaecol 1983;90:628-32.

6 Anderson GM, Lomas J. Explaining variations in cesarean section rates: patients, facilities, o policies? Can Med Assoc $\mathcal{7}$ 1985;132:253-9

Collea JV, Chein C, Quilligan EJ. The randomized management of term frank breech presentation a study of 208 cases. Am f Obstet Gynecol 1980;137:235-42.

Paul RH, Phelan JP, Yeh S. Trial of labor in the patient with a prior cesarean birth. Am $\mathcal{J}$ Obste Gynecol 1985;151:297-304

9 Banta HD, Thacker SB. Costs and benefits of electronic fetal monitoring: a review of the literature. Washington, DC: United States Department of Health, Education, and Welfare, 1979. (DHEW Publication No (PHS 79-3245)

10 Hurst M. Sumnev PS. Childbirth and social class: the case of a caesarean delivery. Soc Sci Med $1984: 18: 621-31$

1 Havnes de Regt R, Minkoff HL, Feldman J, Schwarz RH. Relation of private or clinic care to the cesarean birth rate. $N$ Engl f Med 1986;315:619-24

12 Anonymous. President's programme: can rise in c-section be reversed? American College of Obstetricians and (jvnecologists News Bulletin 1987;20:1(6).

13 Lomas J, Enkin M. Variations in operative delivery rates. In: Enkin MW, Keirse MJ, Chalmers I, eds. Effective care in pregnancy and childbirth. Oxford: Oxford University Press (in press).

14 Anderson GM, Lomas J. Determinants of the increasing cesarean birth rate: Ontario data, 1979 1982. N Engl f Med 1984;311:887-92.

15 Shiono PH, McNellis D, Rhoads GG. Reasons for the rising cesarean delivery rates: 1978-1984 Obstet Gynecol 1987;69:696-700

16 Gibbs RS. Infection after cesarean section. Clin Obstet Gynecol 1985;28:697-9.

17 Finley BE, Gibbs $\mathrm{CE}$. Emergent cesarean delivery in patients undergoing a trial of labor with a transverse lower-segment scar. Am f Obstet Gynecol 1986;155:936-9.

18 National Institutes of Child Health and Diseases Task Force on Cesarean Childbirth. Report. Bethesda, Maryland: National Institutes of Health, 1981. (DHHS Publication No (NIH) $82-2067$ ).

19 Gleicher $N$ Cesarean section rates in the United States. The short-term failure of the Nationat Consensus Development Conference in 1980. FAMA 1984;252:3273-6.

20 Shiono PH, Fielden JG, MCNellis D, Rhoads GG, Pearse WH. Recent trends in cesarean birth and trial of labor rates in the United States. JAMA 1987:257:494-7.

21 Kosecoff J, Kanouse DE, Rogers WH, McCloskey L, Monroe Winslow C, Brook RH. Effects of the National Institutes of Health Consensus Development Program on physician practice. AMA 1987;258:2708-13

22 Panel and Planning Committee of the National Consensus Conference on Aspects of Cesarean Birth. Indications for cesarean section: final statement of the panel of the National Consensu Conference on Aspects of Cesarean Birth. Can Med Assoc J 1986;134:1348-52.

23 Lomas J, Anderson G, Enkin M, Vayda E, Roberts R, MacKinnon B. The role of evidence in the consensus process: results from a Canadian consensus exercise. 7AMA 1988;259:3001-5.

\title{
Anyone for tetanus?
}

\section{Boosters advised for adults on every decade birthday}

An active immunisation programme has meant that tetanus has virtually ceased to afflict children in Britain. In adults there are encouraging downward trends in incidence and death, but about 30-50 cases still occur each year-and between $10 \%$ and $60 \%$ of these patients die. Half the cases occur in patients over 65 , and more than half of these follow gardening injuries; the prognosis worsens with age. ${ }^{1.3}$ Rare events remain someone else's concern till they strike at home, and Bibby and Dixon's report on the low cover against the disease among their adult patients stems from a death in their own practice (p 598).

Bibby and Dixon have carried out a simple and probably widely reproducible survey of the records of 600 adults attending their surgery. Only $13 \%$ were certainly protected against tetanus. Even if the stringency of their judgments was relaxed to fit with the 10 year pattern of booster injections widely recommended on both sides of the Atlantic, around three quarters of their patients were still at risk. This figure is in line with estimates from elsewhere: Grabenstein et al reported that $53 \%$ of those over 60 reporting for influenza immunisation were inadequately protected against tetanus ${ }^{4}$; and Williams et al found that $40-80 \%$ were unprotected in their review. ${ }^{3}$

The theoretical work from which immunisation policies will evolve demands complicated mathematical projections. The standard recent work comes from Denmark, where Simonsen et al studied rates of loss of protection under different circumstances. 'They report that $28 \%$ of patients are unprotected 25-30 years after primary immunisation if no booster has been given. They believe that immunity lasts longer after revaccination than after primary vaccination. They find only one (doubtful) case of tetanus reported in a patient within five years after receiving primary protection but were not able to comment on whether revaccination on its own at injury guarantees cover. Recognising the risks of hyperimmunisation (neuropathy and anaphylaxis) with too frequent boosting, they advise primary immunisation in infancy, a boost at five years, a further boost at 25 years, and then boosts every 20 years.

This is where theory and practice become uncomfortable bedfellows. Patients' ability to remember their past medical histories is inexact over even short periods of time, and they are unlikely to recollect accurately the dates of injections received more than 10 years previously. The average patient changes doctor about once every 10 years, and the transfer of records between practices means that clinical and administrative information may be lost. It seems wise to prefer revaccination every 10 rather than every 20 years, and arranging this on the decade could add point to the growing fashion of celebrating 40th, 50th, and other similar anniversaries in style. For the patients currently attending the surgery whose immunity is uncertain I recommend a full course for any adult never before immunised (and that means anyone over 40 until proved otherwise) and a single opportunist injection for anyone previously covered but not boosted within 10 years. Once this has been achieved clean trauma need cause no anxiety and dirty wounds need a booster only if the last one was more than five years previously. For those with injuries whose previous immunity is unknown I advise toxoid for all wounds and human tetanus immune globulin as well for dirty ones.

Formulating a biologically appropriate policy is, however, not the only issue: problems in primary care also prevent immunisation of everybody. Firstly, the information overload 
that destroyed the informativeness (as against volume) of hospital records in the late 1960s now threatens to do the same to general practice records, and we must support the current pressure being put on practices to have summaries of the health and history of their patients. The ideal format is still to be described, and computers are as likely to add to the problems as to solve them unless the purposes of both the record and the summary are properly thought through.

Secondly, the list of screening, preventive, and educational tasks being allotted to primary care teams is getting out of hand. These teams should take the main responsibility for the early months or years of life, and considerable discussion is taking place over the best way to balance autonomy against intervention in the elderly. ${ }^{6}$ But a more informed discussion is needed on the proper balance (both clinical and economic) between opportunistic and systematic screening and recall systems for people in mid-life. The problem of both the carers and the public forgetting could be minimised by using the decade birthday, which would minimise the risks of patients missing out because of geographical mobility or infrequent use of health services. It would also put a sensible ceiling on what seems likely to become extraordinarily expensive systems of pursuing "non-compliant" patients, who might in truth end up healthier for having taken responsibility for their own health.

And, thirdly, as the most important negotiations on general practitioner contracts for two decades move to a crucial stage we must warn against the easy attractiveness of measurable but meaningless performance indicators. The philosophy of accountability is not the problem-just the way in which it is to be achieved. Quick solutions will be worse than the problems they aim at preventing.

Professor of General Practice,

J G R HOWIE

University of Edinburgh,

Levinson House,

Edinburgh EH8 9DX

1 Public Health Laboratory Service Communicable Disease Surveillance Centre. Tetanus surveillance: England and Wales, 1981-3. Br Med f 1985;290:696-7

2 American College of Emergency Physicians. Tetanus immunization recommendations for persons seven years of age and older. Ann Emerg Med 1986;15:1111-2.

Williams WW, Hickson MA, Kane MA, Kendal AP, Spika JS, Hinman AR. Immunization policies and vaccine coverage among adults. The risk for missed opportunities. Ann Intern Med 1988;108:616-25

4 Grabenstein JD, Smith LJ, Carter DW, Engler RJ, Evans R, Summers RJ. Comprehensive immunization delivery in conjunction with influenza vaccination. Arch Interm Med 1986;146:

5 Simonsen O, Bentzon MW, Kjeldsen K, Venborg H-A, Heron 1. Evaluation of vaccination requirements to secure continuous antitoxin immunity to tetanus. Vaccime 1987;5:115-22.

6 Porter AMI. The Edinhurgh hirthday card project. London: Royal College of General Practitioners, 1987. Occasional paper No 35 .

\section{Oestrogens and cardiovascular disease}

\section{Postmenopausal oestrogens seem to reduce coronary heart disease}

The low rates of coronary heart disease in premenopausal women were one justification for an early randomised trial of exogenous oestrogens in the secondary prevention of coronary heart disease in men. The trial was abandoned because the treatment caused more coronary disease. ' Since the 1970s the deleterious effect of oral contraceptives on mortality and morbidity from cardiovascular disease has been confirmed: the attributable risks are greater in smokers and older women. ${ }^{23}$ These findings refer, however, to older preparations and to Western populations with high rates of cardiovascular disease. The risks associated with modern oral contraceptives seem to be lower and are under investigation. ${ }^{45}$

The cardiovascular risks of oral contraceptives are related to both the oestrogen and the progestogen dose through various mechanisms. ${ }^{+}$The adverse effect of progestogens on high density lipoprotein cholesterol concentrations seems to be an important pathway for increasing the risk of coronary heart disease, and the venous thromboembolic risks are related to the oestrogen dose. ${ }^{2}$

Because of the effects of oral contraceptives researchers initially expected that oestrogens given after the menopause would increase mortality from cardiovascular disease. Because oestrogens are used so widely after the menopause, especially among American women, it is important that their effects should be clarified-even a small effect would be of major importance to public health. ${ }^{6}$ Although published reports on the cardiovascular effects of postmenopausal oestrogens have been confusing, ${ }^{7}$ the recent publication of several prospective studies has clarified matters.

The Framingham study found an increase of half in the risk of cardiovascular morbidity in users compared with non-users but no increase in the total mortality. This study looked at a cohort of 1234 postmenopausal women, a quarter of whom had used conjugated equine oestrogens between 1962 and $1972 .{ }^{8}$ In contrast, the nurses' health study of 32317 postmenopausal women studied in the late 1970 s found an appreciable protective effect of postmenopausal oestrogens on coronary heart disease; just over half of the nurses had used oestrogens. ${ }^{9}$ The discrepancy between these two studies is probably explained by their different methods: a more rigorous reanalysis of the Framingham data, with harder end points and a modified definition of oestrogen use, found that oestrogens used after the menopause in women aged 50-59 protected against cardiovascular disease; an adverse effect was found in only a few aged 60-69. ${ }^{10}$

A well executed study of deaths in a cohort of white women participating in the lipid research clinics prevalence study and seen initially between 1972 and 1976 showed a highly protective effect of non-contraceptive oestrogens on mortality from cardiovascular disease. " The effect seemed to be mediated through an increase in high density lipoprotein concentrations; it seems unlikely to have been caused by a selection bias for oestrogen use-that is, women at low cardiovascular risk preferentially using oestrogens. The Walnut Creek prospective study found that postmenopausal oestrogens have a protective effect on mortality from all causes, including violent death, ${ }^{12}$ which suggests a selection bias. The prospective study with the largest number of hard end points was conducted in a Californian retirement community, and it too found that oestrogens reduced deaths from acute myocardial infarction. ${ }^{6}$ Postmenopausal oestrogens also seem to eliminate the increased risk of coronary heart disease in women who have had bilateral oophorectomy. ${ }^{13}$

Thus the results from all community based prospective studies, except perhaps the Framingham study, show that postmenopausal oestrogens offer substantial protection against the risk of cardiovascular disease. Most of the community based case-control studies have also found a protective effect. ${ }^{7}$ All these prospective studies, however, have been conducted in the United States. Only one pilot case-control study has been reported from Britain, ${ }^{14}$ and 